\title{
HET VERSCHIJNSEL VAN DE BELASTINGAFWENTELING
}

\author{
door Dr. N. H. Douben
}

\section{Inleiding}

De vraag of belastingen kunnen worden afgewenteld, houdt tal van economisten, fiscalisten, en politici reeds lang bezig. In de theoretische economic en met name in de leer van de openbare financiën heeft men veel aandacht aan dit probleem geschonken. Daarvan getuigt een indrukwekkende lijst van publikaties over dit onderwerp. Interessant is daarbij dat de verschillende auteurs allen de term „afwenteling" gebruiken, terwijl zij er vaak uiteenlopende verschijnselen mee aangeven. Hier treffen we soms eenzelfde begripsverwarring aan als die welke optreedt indien verschillende schrijvers de term ,inflatie" hanteren en daarmee verschillende dingen op het oog hebben. Sommigen stellen afwenteling gelijk aan prijsstijging (van eindprodukten), anderen bedoelen er een daling van de beloningsvoet van produktiefaktoren mee en een derde groep verstaat onder afwenteling: het handhaven van het beschikbare reële inkomen van het belaste subjekt.

Deze meervoudige begripsinhoud welke aan de term afwenteling vaak wordt gegeven, heeft wel eens tot onvruchtbare discussies geleid, hetgeen de neiging deed ontstaan deze term niet meer te hanteren, doch in elke casuspositie aan te geven welke bepaalde gevolgen van de belastingheffing werden beschouwd. Het lijkt ons niet noodzakelijk de term afwenteling te vermijden teneinde toch tot een zinvolle discussie of probleemstelling te kunnen komen. Dit temeer daar het verschijnsel van de afwenteling steeds in één adem genoemd wordt met de problematiek van de herverdelende werking van de belastingen, welke laatste afhankelijk wordt gesteld van het al dan niet in sterke mate aanwezig zijn van afwentelingsmogelijkheden. Om dit duidelijk te maken wordt in dit artikel eerst het kenmerkende aspekt van het afwentelingsbegrip besproken, vervolgens zal aandacht worden geschonken aan de „,klassieke” indeling van de reakties op de belastingheffing, en tenslotte wordt getracht om voor enkele gevallen een concrete maatstaf voor de meting van de afwenteling aan te geven.

\section{De essentie van het afwentelingsbegrip}

Het optreden van afwenteling van belastingen betekent in zijn algemeenheid dat ook anderen dan degene die de belastingen moet betalen een vermindering van hun beschikbare reële inkomen ervaren ten gevolge van het feit, dat de belastingbetaler in staat is via de economische kringloop zijn eigen beschikbare reële inkomen met minder te laten dalen dan overeenkomt met de (hogere) belastingheffing. ${ }^{1}$ ) De essentie van het afwentelingsbegrip is dus hierin gelegen dat niet degene die de belasting formeel moet betalen ook zijn beschikbare reële inkomen met het belastingbedrag ziet dalen, maar dat hij door een verlaging van het beschikbare rëele inkomen van andere economische subjekter de druk van de belasting geheel of gedeeltelijk weet over te dragen op andere participanten in het (nationale) inkomen. Zowel bij een gegeven omvang van het totale inkomen als bij een groeiend inkomen

1) Zie bijvoorbeeld: M. J. H. Smeets, De economische betekenis van de belastingen, Amsterdam 1954, pag. 64; C. Goedhart, Hoofdlijnen van de leer der openbare financiën, Leiden 1967, pag. 129 en H. C. Recktenwald, Steuerüberwalzungslehre, Berlijn 1966, pag. 41 en 82. 
betekent afwenteling dat een groter aandeel van de overheid in het particuliere inkomen tot gevolg heeft, dat het aandeel van de belastingbetaler met minder daalt dan de stijging van het overheidsaandeel.

De basisgrootheid waaraan de problematiek van de afwenteling wordt gerelateerd is dus het inkomen. De belastingheffing houdt immers een aanslag van de fiscus op het inkomen van de contribuabele in en daartegen tracht deze laatste zich te wapenen.

Deze afbakening van het afwentelingsvraagstuk tot veranderingen in het beschikbare reële inkomen impliceert niet dat de analyse van de afwenteling nu ook een partieel karakter heeft. In deze opvatting wordt namelijk uitdrukkelijk rekening gehouden met het feit dat de belastingheffing gepaard gaat met een groot aantal economische effekten die alle hun invloed uitoefenen op de inkomensverdeling in de particuliere sektor. Voor de bepaling van het afwentelingsbegrip zijn niet al deze effekten direkt van belang, wel oefenen zij indirekt invloed uit op de uiteindelijke afwentelingsresultaten. Door de inhoud van het afwentelingsbegrip nauwkeurig af te grenzen wordt ook niet getornd aan de veelzijdigheid van het mechanisme dat in de economische kringloop aanwezig is en dat de mogelijkheden tot het realiseren van de belastingafwenteling in zich draagt. In de oude literatuur over de afwenteling van de belastingen werd wél een aanzienlijke beperking aan het afwentelingsmechanisme opgelegd, waardoor de „klassieke” behandeling van dit probleem een sterk partieel karakter droeg. Voordat wordt ingegaan op de nadere concretisering van het hier aangegeven afwentelingsbegrip zal daarom eerst enige aandacht worden geschonken aan de „klassieke visie” op dit vraagstuk.

\section{De klassieke visie en haar bezwaren}

In de klassieke visie wordt het verschijnsel van de belastingafwenteling gekoppeld aan de prijsvorming van eindprodukten en van produktiefaktoren. Daarbij wordt er impliciet van uitgegaan dat de produktie- en afzetstruktuur gegeven zijn, waardoor van het bestaan van substitutie-effekten wordt geabstraheerd. De prijsvorming in deze enge zin opgevat (dus zonder substitutiemogelijkheden) wordt vaak zelfs als het wezenskenmerk van de belastingoverdracht gezien. De afwenteling wordt daarmede beperkt tot die gevallen, waarin de handhaving van het beschikbare reële inkomen tot stand komt door middel van een verhoging van de prijzen der eindprodukten of een verlaging van de prijzen der produktiefaktoren, van de grond- en hulpstoffen, alsmede non-faktordiensten. In het eerste geval is er dan sprake van voortwenteling, in de andere van terugwenteling. Andere reakties die door de belastingheffing worden opgeroepen en die - anders dan via de primaire prijseffekten - van invloed zijn op de inkomensverdeling worden geheel buiten het afwentelingsbegrip gehouden. De effekten van de belastingheffing worden in de klassieke visie namelijk ingedeeld in:

a) ontwijking (door de belaste handeling achterwege te laten);

b) compensatie (door opvoering van de aktiviteit) en

c) afwenteling (door middel van voort-en/of terugwenteling).

Zoals reeds is opgemerkt wordt de term afwenteling hier gereserveerd voor de invloed die het beschikbare reële inkomen van de belastingbetaler ondergaat ten gevolge van de (door de belastingheffing) opgeroepen prijsmutaties. Deze beperking van het afwentelingsmechanisme en het afwentelingsbegrip vindt zijn oor- 
zaak niet in de economische theorie, maar is toe te schrijven aan de fiskaal-juridische benadering van het afwentelingsvraagstuk. In een economisch model is het immers niet logisch om deze verschillende effekten van de belastingheffing te isoleren, want daardoor wordt de algemene interdependentie die een belangrijke rol speelt in de kringloop op volkomen willekeurige wijze afgekapt. Het klassieke af wentelingsbegrip mist daardoor de algemeenheid en de reikwijdte die in verband met de omvang van het afwentelingsverschijnsel der belastingen aan dit begrip moeten worden gesteld. Met andere woorden: het klassieke afwentelingsbegrip heeft een sterk partieel karakter omdat de economische relaties kunstmatig worden gekortwiekt. Een van de meest nadelige consequenties van deze begripsvorming is geweest, dat er een oneindig aantal casusposities werd onderscheiden, afhankelijk van marktvorm en vraag- en aanbodelasticiteiten, die een bevredigende benadering van het afwentelingsvraagstuk in de weg hebben gestaan.

Teneinde nu de algemene interdependentie tussen de economische variabelen tot hun recht te laten komen en een meer algemene afwentelingstheorie te ontwikkelen, kan de volgende weg worden bewandeld. Er moet rekening worden gehouden met alle effekten die ten gevolge van een belastingverhoging invloed uitoefenen op het beschikbare reële inkomen van de belastingplichtigen. Het totaal-effekt van de belastingverhoging moet echter geheel geïsoleerd worden van de autonome wijzigingen in andere variabelen, d.w.z. alle andere autonome grootheden (behalve de belastingtarieven) moeten constant worden gehouden. Dit laatste nu is mogelijk geworden door te werken met vergelijkingenstelsels die een bepaald economisch model formaliseren. Door uit zo'n model de herleide vormvergelijking te berekenen voor het beschikbare reële inkomen van de contribuabele en daarbij in die vergelijking alleen het belastingtarief te laten muteren, kan een algemene conclusie ten aanzien van de afwenteling worden getrokken. Afhankelijk van het concrete model zal dan de uitkomst variëren, doch de interdependentie wordt geen geweld meer aangedaan. Het belangrijkste bezwaar van de klassieke visie op het afwentelingsbegrip en afwentelingsmechanisme, namelijk de partiële benadering, is daarmede uit de weg geruimd.

\section{Nadere concretisering noodzakelijk}

Ofschoon in deze beschouwing de nadruk wordt gelegd op de begripsbepaling van de belastingafwenteling in het algemeen kan hiermede toch niet worden volstaan, indien men wil nagaan hoe de afwenteling van een concrete belasting gemeten kan worden. Voor de verschillende economische subjekten en voor de verschillende belastingen moet het concrete afwentelingsbegrip daarom exact worden gedefinieerd. Uitgangspunt is daarbij, dat wordt aangenomen dat elk economisch subjekt er naar streeft zijn beschikbare reële inkomen tenminste te handhaven, want alleen dan lokt belastingheffing af wentelingsreakties uit.

Het is niet de bedoeling om in dit artikel alle afwentelingsmaatstaven die in voorkomende concrete gevallen kunnen worden toegepast de revue te laten passeren. Hier wordt slechts bij een tweetal stilgestaan, namelijk de afwenteling van de vennootschapsbelasting ( $v \mathrm{pb}$ ) en de af wenteling van de inkomstenbelasting (ib). Voor andere belastingen en andere situaties kan een analoge redenering worden gevolgd. 
Eerst wordt ingegaan op de afwenteling van de $v p b^{2}$ ). Nu eist de doelmatigheid dat het concrete af wentelingsbegrip zal moeten aansluiten bij de inkomensvorming binnen de onderneming. Het gaat er nu immers om duidelijk aan te geven wat hier onder handhaving van het beschikbare reële ondernemingsinkomen wordt verstaan, daar dit de kern van het afwentelingsbegrip uitmaakt. Zonder bezwaar kan worden gesteld dat het inkomen dat voortvloeit uit het ondernemen door de winst wordt uitgedrukt. Handhaving van de winst - ondanks de hogere vpb - betekent in onze gedachtengang dat deze belastingheffing volledig is afgewenteld. Daarbij blijft echter discussie mogelijk over de vraag wat winsthandhaving exact inhoudt; betekent dit handhaving van het absolute winstbedrag of handhaving van de relatieve winst, zoals: winst ten opzichte van de omzet, winst gerelateerd aan het geinvesteerde vermogen, of winst in relatie tot de totale toegevoegde waarde ${ }^{3}$ )? Wij beschouwen deze opsomming als limitatief en sluiten daarmee de prijsstijging van eindprodukten als maatstaf voor de afwenteling aldus uit. Deze opvatting kan kort worden geargumenteerd.

De prijsstijging op zich geeft geen enkele informatie omtrent de mate waarin het winstinkomen gehandhaafd kan worden. Zij geeft alleen aan, dat er afwentelingsreakries in het leven zijn geroepen, meer niet. In hoeverre de afwenteling slaagt kan niet door middel van de prijsstijging worden uitgedrukt, ook al is dit het enige middel om de afwenteling te realiseren, zoals bij de vrije beroepen veelal het geval zal zijn.

De keuze die nu nog overblijft is dus: absolute winst, winstmarge, rentabiliteit en winstaandeel in de toegevoegde waarde.

Al deze potentiële maatstaven voor de concretisering van de afwenteling der vpb hebben ieder hun voor- en nadelen welke tegen elkaar moeten worden afgewogen; dan pas kan een definitieve keuze worden gedaan. Nemen we nu een situatie van economische groei als uitgangspunt dan is het duidelijk dat de absolute winst (na aftrek van de vpb) hier als concrete afwentelingsmaatstaf moet worden verworpen. In een dergelijke toestand betekent de handhaving van het absolute winstbedrag toch een daling van de inkomenspositie van de onderneming ten opzichte van de groeiende andere inkomenscategoriëen (zoals bijv. de lonen en rente over vreemd vermogen). Daarnaast betekent cen gelijk absoluut winstbedrag bij stijgende prijzen (welke door de afwentelingsreakties kunnen worden opgeroepen) dat de reële absolute winst is gedaald ${ }^{4}$ ).

Daar hier echter speciaal het ,groeiklimaat" waarir de onderneming werkzaam is in het oog wordt gehouden, is het noodzakelijk het accent te leggen op een relatieve winstmaatstaf. Hiervoor worden veelvuldig de winstmarge en het rendement gebruikt. Het belangrijkste bezwaar tegen het gebruik van deze grootheden als afwentelingsmaatstaf van de vpb ligt hierin, dat zij geen zuivere inkomensmaatstaven zijn. Bij de winstmarge wordt immers de absolute winst gerelateerd aan de omzet en bij het rendement is de verhouding tussen winst en omvang van het geinvesteerde vermogen relevant. Aan het verloop van winstmarge en rendement kan dan ook niet worden afgemeten of de positie van de winst ten opzichte van de

$\left.{ }^{2}\right)$ Zie in dit verband ook: N. H. Douben, Afwenteling van de vennootschapsbelasting, Leiden 1967, hoofdstuk 1, waarin uitvoeriger op de hier behandelde problematiek wordt ingegaan.

3) Onder toegevoegde waarde wordt hier verstaan: alle inkomens die in de onderneming zijn gevormd, dus lonen en salarissen, rente, pacht en winst vóór aftrek van belastingen.

*) Dit geldt natuurlijk ook zonder dat er sprake is van economische groei. 
andere inkomens al dan niet is veranderd. Dit manco maakt beide grootheden ongeschikt om als af wentelingsmaatstaf van de vpb te dienen.

De derde relatieve winstmaatstaf, de winst als andeel in de toegevoegde waarde, heeft op de beide voorgaande maatstaven vóór, dat het wél een zuivere inkomensmaatstaf is. Deze maatstaf is dan ook bij uitstek geschikt om in dit geval de afwenteling uit te drukken. Een constante winstquote (na aftrek van de vpb) betekent namelijk dat de verhouding tussen de winst (na aftrek van de vpb) en de totaliteit van de overige inkomens ongewijzigd is gebleven; een daling van deze quote geeft aan dat handhaving van het beschikbare reële winstinkomen niet mogelijk is geweest. Met behulp van deze indicator kan ook gemakkelijk worden aangegeven in welke mate de afwenteling is gerealiseerd. Een voorbeeld kan dit verduidelijken.

Stel dat de toegevoegde waarde van een N.V. in de uitgangssituatie als volgt is samengesteld:

$\begin{array}{lr}\text { beschikbare winst } & 25 \% \\ \text { vennootschapsbelasting } & 10 \% \\ \text { loonsom } & 60 \% \\ \text { betaalde rente } & 5 \% \\ & -100 \% \\ \text { toegevoegde waarde } & \end{array}$

In de volgende periode wordt de vpb verhoogd, waardoor haar aandeel in de toegevoegde waarde stijgt tot $20 \%$. Nu kunnen drie verschillende situaties ontstaan, zoals uit de volgende opstelling blijkt.

situatie

I II

III

beschikbare winst

vennootschapsbelasting

loonsom

betaalde rente

$\begin{array}{rr}15 \% & 20 \% \\ 20 \% & 20 \% \\ 60 \% & 56 \% \\ 5 \% & 4 \%\end{array}$

$25 \%$

$20 \%$

$51 \%$

$4 \%$

toegevoegde waarde

$100 \%$

$100 \%$

$100 \%$

Vergelijking van de uitgangssituatie met die van de verdeling der toegevoegde waarde in situatie I doet meteen zien dat de verhoging van het vpb-tarief geheel ten laste van de beschikbare winstquote is gekomen, zodat hier geen sprake is van afwenteling. In situatie II is de beschikbare winstquote gestegen ten opzichte van situatie I, waardoor de afwenteling gedeeltelijk geslaagd is. De mate van af wenteling in situatie II kan namelijk berekend worden als:

$$
\frac{20-15}{10} \times 100 \%=50 \%
$$

De afwenteling is hier voor de helft gerealiseerd. Het cijfer 20 in de breuk geeft aan: de feitelijk beschikbare winstquote na vpb-verhoging; 15 duidt aan: de beschikbare winstquote indien geen afwenteling optreedt en 10 is de verhoging van de vpbals percentage van de toegevoegde waarde. 
Gemakkelijk is nu ook in te zien dat in situatie III van volledige afwenteling kan worden gesproken: de beschikbare winstquote na vpb-verhoging is immers gelijk aan die vóór de verhoging van de vpb. Toepassing van de breuk voor de mate van afwenteling levert nu $100 \%$ op:

$$
\frac{25-15}{10} \times 100 \%=100 \%
$$

De beschikbare winstquote leent zich zowel voor de bepaling van de afwenteling der vpb op micro als op macro economisch niveau. De toegevoegde waarde van alle N.V.'s tesamen is immers niets anders dan het nationale inkomen voorzover gevormd in de sektor der N.V.'s. Wel dient hier nog te worden opgemerkt dat voor de individuele onderneming ook aan de winstquote als afwentelingsmaatstaf een bezwaar blijft kleven, namelijk dat deze indicator abstraheert van de ontwikkeling van het marktaandeel van de onderneming. Zou voor een afzonderlijke onderneming het marktaandeel teruggelopen zijn ten gevolge van de afwentelingsreakties, doch de beschikbare winstquote constant zijn gebleven, dan is het moeilijk staande te houden dat de afwenteling volledig geslaagd is. Voor de individuele onderneming dient deze maatstaf dan ook te worden aangevuld met de randvoorwaarde dat het marktaandeel constant dient te blijven. Deze randvoorwaarde geldt ook bij toepassing van de andere relatieve maatstaven.

Meting van de afwenteling van de inkomstenbelasting (incl. loonbelasting) dient - evenals de maatstaf voor de afwenteling der vpb - ook met behulp van een relatieve grootheid te geschieden. De afwenteling komt nu tot uitdrukking in een meer gedénivelleerde personele inkomensverdeling vóór aftrek van deze belasting. Voor de totaliteit van inkomenstrekkers kan door middel van de Lorenzcurve theoretisch het verschijnsel van de afwenteling worden bepaald. Daartoe wordt de volgende figuur getekend.

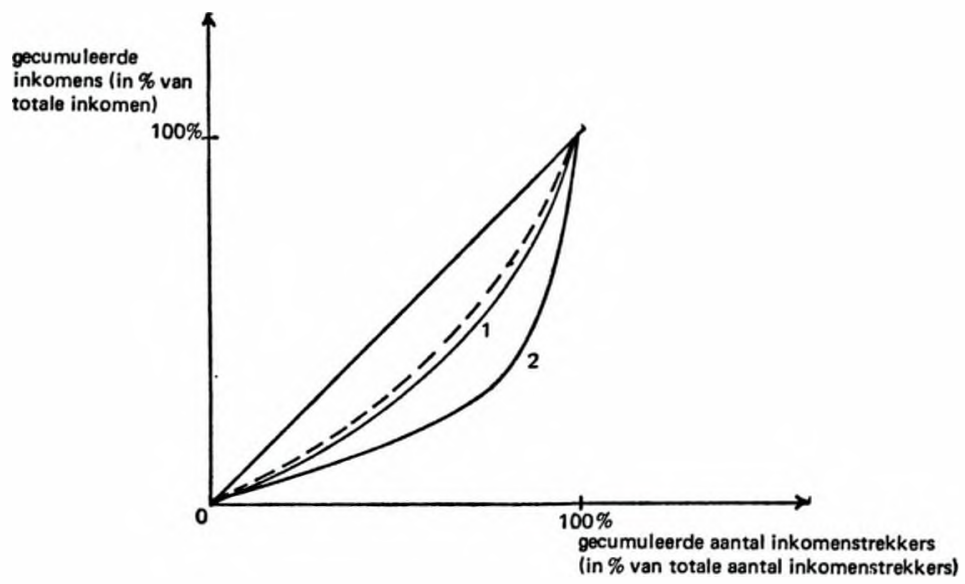

Op de vertikale as staan de gecumuleerde inkomens afgezet en de horizontale as geeft de gecumuleerde aantallen inkomenstrekkers aan. De oorspronkelijke personele inkomensverdeling vóór belastingen en bij het aanvankelijke (lage) tarief wordt aangegeven door curve 1 . Treedt nu ten gevolge van tariefsverhoging c.q. 
invoering der $\mathrm{ib}$ afwenteling op, dan gaat de kromme 1 naar rechts verschuiven en de verdeling wordt dan (vóór aftrek van de hogere belasting) door curve 2 aangegeven. De af wenteling is groter naarmate curve 1 en 2 verder uit elkaar liggen. De inkomensverdeling ná aftrek van belastingen wordt door de gestippelde curve voorgesteld; de afwenteling kan dus ook worden gemeten door de gestippelde curve en curve 1 met elkaar te vergelijken: naarmate beide curven dichter bij elkaar liggen, is de afwenteling groter. Vallen deze beide curven samen dan is er door de belastingheffing geen verandering in de beschikbare inkomensverhoudingen ontstaan hetgeen betekent dat de progressie van de ib geheel is afgewenteld.

Met behulp van deze eenvoudige methode kan ook een onderzoek worden ingesteld naar de ontwikkeling van de verhouding tussen de beschikbare inkomens van personen die op verschillende plaatsen in de inkomenspyramide verblijven. Zo kan bijvoorbeeld de verhouding tussen het beschikbare inkomen van iemand uit het hoogste en laagste deciel van de inkomensopbouw worden vergeleken. Is die verhouding ondanks gewijzigde ib-tarieven constant dan zou dit een aanwijzing kunnen inhouden dat in dit geval de progressie afgewenteld is geworden. Een analoog resultaat kan worden verkregen door de beschikbare inkomens van personen met verschillende funkties (bij gestegen belastingtarieven) te vergelijken. In de overheidssfeer zou hierbij gedacht kunnen worden aan de verhouding tussen de beschikbare salarissen van bijvoorbeeld een secretaris-generaal en een schrijver, of een hoogleraar en een onderwijzer bij het lager onderwijs. Ook bij de concretisering van het afwentelingsbegrip voor de ib geldt weer dat het doel van de probleemstelling grote invloed heeft op de keuze van de concrete afwentelingsmaatstaf.

\section{Slotbeschouwing}

In het voorafgaande is getracht een begripsbepaling van het verschijnsel der belastingafwenteling te geven zonder dat werd ingegaan op een of andere concrete situatie. De kern van de afwentelingsproblematiek wordt vaak in discussies niet nauwkeurig in het oog gehouden, waardoor gemakkelijk verwarring tussen het afwentelingsbegrip zelf en de wijzen waarop de afwenteling kan worden gerealiseerd, ontstaat. Om de inhoud van het begrip afwenteling duidelijk aan te geven werd daarom in dit artikel de nadruk gelegd op de essentie van de afwenteling. Deze wordt gevonden in het inkomensaspekt dat de kern van de afwentelingsproblematiek bevat. Af wenteling houdt in dat de aanslag van de fiscus op het beschikbare reële inkomen van het belaste subjekt niet (volledig) slaagt, doordat het subjekt de mogelijkheid heeft de hogere belasting (geheel dan wel gedeeltelijk) op het beschikbare reële inkomen van anderen te laten drukken, zodat zijn eigen reële inkomen (geheel dan wel gedeeltelijk) gehandhaafd blijft ${ }^{5}$ ). Voor uiteenlopende situaties en belastingen kunnen dan verschillende concrete afwentelingsmaatstaven worden gehanteerd waarvan er hier twee werden besproken.

5) Hier zij nog opgemerkt dat sommige schrijvers van groeitheoretische beschouwingen de winst (vnl. van N.V.'s) niet als een vrij beschikbare inkomenscomponent beschouwen, doch macro economisch als kostenfaktor van de groei zien. Deze visie delen wij ook. Wij zijn het echter niet eens met de opmerking die aan deze visie wordt vastgeknoopt, namelijk dat het kapitaalrendement en niet het winstaandeel in de toegevoegde waarde als een adequate afwentelingsmaatstaf moet worden beschouwd, omdat de winst niet vrij consumptief kan worden aangewend (zonder de groei te schaden). De reden voor deze afwijzing is dat het niet gaat om de besteding van het inkomen als het afwentelingsvraagstuk aan de orde wordt gesteld, doch om de verdeling van het totale inkomen.

m a b blz. 127 